\title{
Pulmonary embolism rule-out criteria (PERC) in pulmonary embolism—revisited: A systematic review and meta-analysis
}

\author{
Balwinder Singh, ${ }^{1}$ Shannon K Mommer, ${ }^{2}$ Patricia J Erwin, ${ }^{3}$ Soniya S Mascarenhas, ${ }^{4}$ \\ Ajay K Parsaik ${ }^{5}$
}

- Additional data are published online only. To view these files please visit the journal online (http://dx.doi.org/10.1136/ emermed-2012-201730)

${ }^{1}$ Division of Pulmonary and Critical Care Medicine, Mayo Clinic, Rochester, Minnesota, USA

2Department of General Surgery, Mayo Clinic,

Rochester, Minnesota, USA ${ }^{3}$ Knowledge and Encounter Research, Mayo Clinic, Rochester, Minnesota, USA ${ }^{4}$ Health Care Management, London Training College, London, UK

${ }^{5}$ Department of Neurology, Mayo Clinic, Rochester, Minnesota, USA

\section{Correspondence to} Dr Balwinder Singh, Division of Pulmonary and Critical Care Medicine, Mayo Clinic, 200, 1 st Street SW, Rochester, MN 55905, USA: singh.balwinder@mayo.edu

Accepted 4 September 2012

Published Online First

4 October 2012

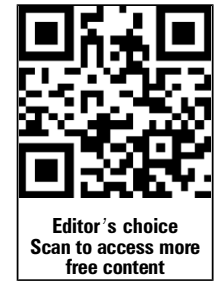

\section{ABSTRACT}

Objectives To perform a systematic review and metaanalysis including all the current studies to assess the accuracy of pulmonary embolism rule-out criteria (PERC) in ruling out pulmonary embolism (PE).

Methods We conducted a comprehensive search of the major databases (Ovid Medline In-Process \& Other NonIndexed Citations, Ovid MEDLINE, Ovid EMBASE, Ovid Psyclnfo, Ovid Cochrane Central Register of Controlled Trials, Ovid Cochrane Database of Systematic Reviews and Scopus) and references of potentially eligible articles and conference proceedings of major emergency medicine organisations through May 2012. We included all original research studies conducted in emergency departments on diagnostic performance of PERC. Two reviewers independently identified the eligible studies and extracted data. Sensitivity, specificity and likelihood ratios were calculated using contingency tables.

Results 12 studies including 13 cohorts (three retrospective, 10 prospective) were included, comprising of 14844 patients from six countries. 12 cohorts were urban and one was rural. Pooled (95\% CI) sensitivity, specificity, positive and negative likelihood ratio were 0.97 (0.96 to 0.98 ), 0.22 (0.22 to 0.23 ), 1.22 (1.16 to 1.29 ) and 0.17 (0.13 to 0.23$)$, respectively. The pooled (95\% Cl) diagnostic OR was 7.4 (5.5-9.8). On metaregression analysis, there was no significant difference between PE prevalence and PERC diagnostic performance (coefficient (SE) of $-0.032(0.022), p=0.173$ ) or on relative diagnostic $\mathrm{OR}(0.97,95 \% \mathrm{Cl} 0.92$ to 1.02$)$. Significant heterogeneity was observed in specificity $\left(\mathrm{I}^{2}=97.4 \%\right)$ and positive likelihood ratio $\left(\mathrm{I}^{2}=89.1 \%\right)$.

Conclusions Because of the high sensitivity and low negative likelihood ratio, PERC rule can be used confidently in clinically low probability population settings.

\section{INTRODUCTION}

Millions of patients present to the emergency department (ED) annually in the USA with common complaints of dyspnoea, chest pain or both $^{1}$ and pulmonary embolism (PE) is potentially a fatal underlying cause. Fear of missing mortal diagnosis often compels emergency physicians to order a D-dimer. Even though D-dimer is a relatively low cost test, it has poor specificity, and therefore often leads to false positive results. Positive D-dimer in turn leads to expensive confirmatory tests such as ventilation perfusion scan, CT-pulmonary angiography and so on. ${ }^{2}$ These confirmatory tests incur significant cost burden on patients, increase length of ED stay and may lead to incidental findings, which further increase anxiety level of patients along with serial imaging studies. $^{3}$

Kline and colleagues developed a clinical decision rule (pulmonary embolism rule-out criteria, PERC) to rule out the PE among patients with low suspicion. ${ }^{4}$ Patients meeting PERC criteria (PERC $(-)$ ) (age $<50$ years, pulse rate $<100 / \mathrm{min}, \mathrm{SpO}_{2}>94 \%$, no unilateral leg swelling, no haemoptysis, no surgery or trauma within 4 weeks, no prior deep vein thrombosis or PE and no oral hormone use) should not require any further testing including D-dimer. PERC rule when applied to the US population yielded similar results; however, the results were inconclusive in European population. ${ }^{4-11}$ Therefore, we conducted a systemic review and meta-analysis reporting the pooled results of all available studies done in different settings and concluded that PERC rule can be used with confidence in various settings with low PE probability. ${ }^{12}$

Recently, Penaloza et al ${ }^{13}$ applied PERC rule alone and combined with revised Geneva score and gestalt clinical probability in a non-selected European population. They reported that PERC rule when combined with gestalt clinical probability can rule out PE in selected group of patients without requiring additional testing. ${ }^{13}$ Therefore, to further strengthen the evidence, we performed an updated systematic review and meta-analysis including additional studies to our previous report to assess the accuracy of PERC in ruling out PE in the ED.

\section{METHODS}

This meta-analysis followed the Preferred Reporting Items for Systematic Review and Meta-analysis statement guidelines. ${ }^{14}$ We conducted a comprehensive search of the major databases (Ovid Medline In-Process \& Other Non-Indexed Citations, Ovid MEDLINE, Ovid EMBASE, Ovid PsycInfo, Ovid Cochrane Central Register of Controlled Trials, Ovid Cochrane Database of Systematic Reviews and Scopus) through August 2011 and updated on 29 May 2012, irrespective of language barrier. In addition, we reviewed the references in potentially eligible articles and conference proceedings of the major emergency medicine organisations to minimise the publication bias. The comprehensive search was designed by an expert librarian (PJE), with inputs from the study investigators (AKP and BS). The detailed search strategy is available as an online supplementary appendix. 
Two reviewers independently screened the titles and abstracts of potentially eligible articles, followed by a comprehensive review of full texts of potentially eligible articles. The study selection criteria were: (1) defined performance of accuracy of PERC to rule out PE, (2) original research and (3) conducted in the ED. We did not limit our search strategy to the publication or language status. Inter-reviewer agreement for study selection during both phases was assessed with Cohen's weighted $\kappa$, and any disagreement was resolved by mutual consensus. Two reviewers independently extracted the data from included studies using the standardised predesigned form, and any disagreement was resolved by mutual consensus. Data points were study characteristics (author, country, publication year, number of patients, study settings, study design, description of study participants and duration of follow-up), subject selection (inclusion and exclusion criteria), PERC classification, outcome definition and measurement, outcomes in PERC positives and negatives, and follow-up. In a study reporting multiple cohorts, each cohort was included separately. ${ }^{12}$ The primary outcome of our study was the diagnosis of PE or venous thromboembolism or death caused by venous thromboembolism within 90 days of initial ED evaluation. For the quality assessment of the study methodology, we used the modified Quality Assessment of Diagnostic Accuracy Studies tool; further details about quality assessment are given elsewhere. ${ }^{12}$ The quality assessment of study methodology was done independently by two reviewers and the inter-reviewer agreement was assessed with Cohen's weighted $\kappa$ and any disagreement was resolved by mutual consensus.

\section{Statistical analysis}

The results were reported as medians with IOR or means with $\mathrm{SD}$ for continuous variables and percentages for the categorical variables. Contingency tables were used to calculate the pooled sensitivity and specificity. Pooled likelihood ratios and diagnostic OR were calculated by random-effects model. The statistical heterogeneity between the studies was quantified with $\mathrm{I}^{2}$ statistic. ${ }^{15} \mathrm{I}^{2}$ values of $<25 \%, 25 \%-50 \%$ and $>50 \%$ represent minimal, moderate and substantial heterogeneity, respectively. A subgroup analysis was performed on the basis of PE prevalence $(<10 \%$ and $\geq 10 \%$ ). Meta-regression with a generalisation of Littenberg and Moses linear model was performed to determine the association between PE prevalence and PERC diagnostic accuracy. All the analyses were performed with Meta-Disc software (Unit of Clinical Biostatistics and the Ramon y Cajal Hospital, Madrid, Spain).

\section{RESULTS}

The study selection flow diagram is shown in figure 1 . In all, 12 studies including 13 cohorts met the inclusion criteria (table 1), comprising of 14844 patients from six countries (USA, UK, Switzerland, France, Belgium and New Zealand). ${ }^{4-11} 13$ 16-18 Twelve cohorts were urban and one was rural, ${ }^{5}$ with three derived retrospectively, ${ }^{6} 1013$ while the rest were derived prospectively. Mean age was 56.7 years, with $63 \%$ female subjects. The inter-reviewer agreement $(\kappa)$ for phase I (title and abstracts) and phase II (full texts) was 0.93 and 0.91 , respectively. Quality assessment of the study methodology is shown in table 2 . The inter-reviewer agreement $(\kappa)$ for the quality assessment of the study methodology was 0.88 . In all the cohorts, study populations appeared unbiased, with no reported implementation of PERC in clinical practice.

Figure 2 demonstrates the pooled performance of the included studies. The pooled ( $95 \%$ CI) sensitivity, specificity, positive likelihood ratio and negative likelihood ratio were 0.97 (0.96 to 0.98$), 0.22$ (0.22 to 0.23 ), 1.22 (1.16 to 1.29 ) and 0.17 (0.13 to 0.23 ), respectively, for PERC alone. Even though minimal decrease was seen in pooled specificity, positive likelihood ratio and negative likelihood ratio after combining the PERC rule with the clinical gestalt, it was clinically insignificant. $^{12}$ The pooled (95\% CI) diagnostic OR was 7.4 (5.5 to 9.8). Significant heterogeneity was observed in specificity $\left(\mathrm{I}^{2}=97.4 \%\right)$

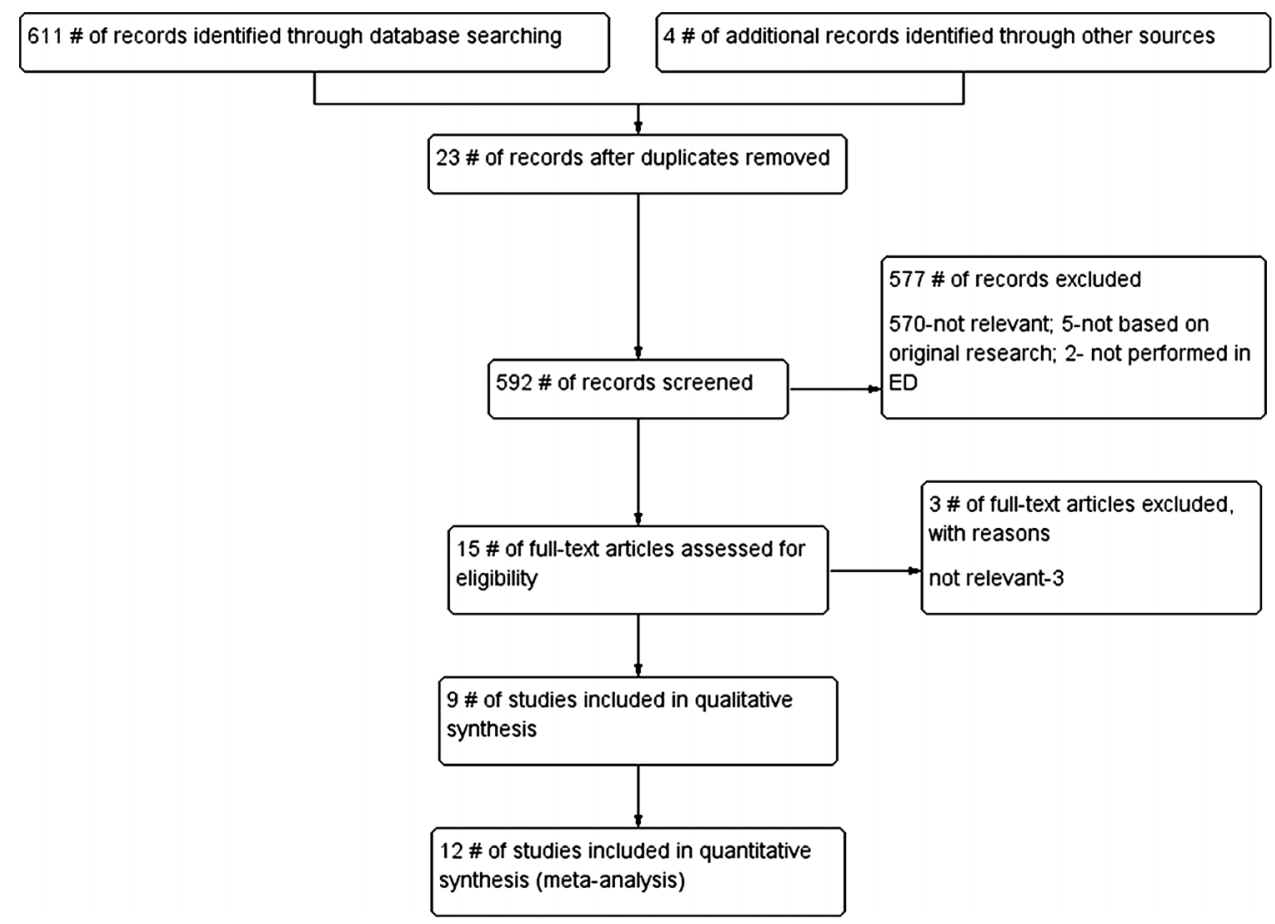

Figure 1 The flow diagram for the selection of studies. 
Table 1 Characteristics of included cohorts

\begin{tabular}{|c|c|c|c|c|c|c|}
\hline Author, year, country & $\begin{array}{l}\mathbf{N} \\
(\% \text { female })\end{array}$ & $\begin{array}{l}\text { Age, mean (SD) or } \\
\text { median (IOR) }\end{array}$ & Subject selection & Outcome definition & $\begin{array}{l}\text { PE } \\
\text { prevalence }\end{array}$ & $\begin{array}{l}\text { Duration of } \\
\text { follow-up, days }\end{array}$ \\
\hline Wolf, 2008, USA & $134(54.0)$ & $58(43-72)$ & $\begin{array}{l}\text { Adults } 18-85 \text { years with clinically suspected PE, chest radiograph and ECG included. } \\
\text { Exclusion: pregnant, haemodynamically unstable, known D-dimer level in recent past }\end{array}$ & $\begin{array}{l}\text { Combination of: } \\
\text { high probability V/Q scan using modified } \\
\text { prospective investigation of PE diagnosis } \\
\text { criteria } \\
\text { intermediate probability V/Q scan with a } \\
\text { high pretest clinical suspicion } \\
\text { contrast-enhanced CT scan chest } \\
\text { pulmonary angiogram } \\
\text { diagnosis of VTE }\end{array}$ & 11.9 & 90 \\
\hline Hogg, 2005, UK & $425(51.1)$ & $38.3(15.0)$ & $\begin{array}{l}\text { Adults ( }>18 \text { years) presented to ED with pleuritic chest pain. } \\
\text { Exclusion: pneumothorax, ECG changes of myocardial infarction, ischaemia or pericarditis, } \\
\text { pregnancy or trauma within } 4 \text { weeks }\end{array}$ & $\begin{array}{l}\text { Combination of: } \\
\text { - high probability V/Q scan with high clinical } \\
\text { probability } \\
\text { - CT-pulmonary angiography } \\
\text { - digital subtraction angiography }\end{array}$ & 5.4 & 90 \\
\hline Kline, 2004, USA, LR & $1427(60.0)$ & $47(17)$ & $\begin{array}{l}\text { Adults ( }>18 \text { years) with clinical suspicion for } P E \text { that emergency physicians believed were } \\
\text { at } L R \text { to justify exclusion of } P E \text { on the basis of a negative } D \text {-dimer }\end{array}$ & $\begin{array}{l}\text { Combination of: } \\
\text { - CT angiography } \\
\text { - CT angiography-venography } \\
\text { V/Q } \text { scan (followed by duplex ultrasound of } \\
\text { the extremities) }\end{array}$ & 8.0 & 90 \\
\hline Kline, 2004, USA, VLR & $382(56.0)$ & $56(18)$ & $\begin{array}{l}\text { Adults ( }>18 \text { years) presenting with shortness of breath but emergency physician stated PE } \\
\text { not the most likely diagnosis }\end{array}$ & $\begin{array}{l}\text { Combination of: } \\
\text { - CT angiography } \\
\text { CT angiography-venography } \\
\text { V/Q scan (followed by duplex ultrasound of } \\
\text { the extremities) }\end{array}$ & 2.4 & 90 \\
\hline Dachs, 2010, USA & 213 & & All the ED patients who underwent a CT scan to rule out PE & CT chest & 8.5 & 90 \\
\hline $\begin{array}{l}\text { Hugli, 2011, } \\
\text { Switzerland, France, } \\
\text { Belgium }\end{array}$ & $1675(56.7)$ & $61(45-76)$ & $\begin{array}{l}\text { Adult outpatients treated in the ED with a clinical suspicion of PE. } \\
\text { Exclusion: contraindication to multidetector CT (MDCT) (ie, allergy to iodine contrast agents, } \\
\text { creatine clearance }<30 \mathrm{ml} / \mathrm{min} \text { or pregnancy), a terminal illness with an expected survival } \\
\text { of }<3 \text { months, a previous documented diagnosis of PE or were receiving anticoagulant } \\
\text { therapy at presentation }\end{array}$ & $\begin{array}{l}\text { Combination of: } \\
\text { positive MDCT or pulmonary angiography } \\
\text { high probability V/0 scan } \\
\text { proximal deep vein thrombosis documented } \\
\text { by compression ultrasonography }\end{array}$ & 21.3 & 90 \\
\hline Beam, 2007, USA & 189 & & $\begin{array}{l}\text { Adults ( }>18 \text { years) with clinical suspicion for PE for whom emergency physicians } \\
\text { considered formal PE evaluation necessary }\end{array}$ & $\begin{array}{l}\text { Combination of: } \\
\triangleright \text { CT scan and } \mathrm{V} / \mathrm{Q} \text { scan }\end{array}$ & 4.2 & 45 \\
\hline $\begin{array}{l}\text { Righini, 2005, } \\
\text { Switzerland }\end{array}$ & $762(58.0)$ & $61(19)$ & Consecutive outpatients suspected of PE & $\begin{array}{l}\text { Combination of: } \\
\text { - clinical probability assessment } \\
\text { D-dimer measurement } \\
\text { - venous ultrasonography (USA) } \\
\text { - helical CT } \\
\text { - pulmonary angiogram }\end{array}$ & 25.7 & \\
\hline Crichlow, 2011, USA & $110(74)$ & $46.4(30.8-62.0)$ & Patients who received CTpulmonary angiography or lower-extremity duplex ultrasonography & $\begin{array}{l}\text { Combination of: } \\
\text { - CT-pulmonary angiography } \\
\text { - Lower-extremity duplex } \\
\text { - Ultrasonography }\end{array}$ & 5.26 & 90 \\
\hline Kline, 2010, USA & 110 & & $\begin{array}{l}\text { ED patients (>17 years) admitted with chief complaints: chest pain, shortness of breath, } \\
\text { respiratory distress, syncope, hypotension,palpitations, cough, altered mental status or } \\
\text { syntax indicating that the patient was sent from outside facility for PE evaluation }\end{array}$ & $\begin{array}{l}\text { Combination of: } \\
\text { - D-dimer }\end{array}$ & 1.74 & 14 \\
\hline
\end{tabular}


and positive likelihood ratio $\left(\mathrm{I}^{2}=89.1 \%\right)$; however, no heterogeneity was observed in the negative likelihood ratio $\left(\mathrm{I}^{2}=0 \%\right)$. The overall proportion of missed PE was $0.3 \%$ (48 of 14844 total cases) when PERC rule was used alone or with revised Geneva score, which further decreased to $0.296 \%$ (44 of 14844 ) when used in combination with clinical gestalt.

For the preplanned subset analysis, studies were divided into two groups based on the PE prevalence $(\geq$ or $<10 \%$ ) (see online supplementary appendix figures S1 and S2). In high and low prevalence groups, pooled ( $95 \% \mathrm{CI}$ ) sensitivity, specificity, positive likelihood ratio and negative likelihood ratio were 0.97 (0.97 to 0.98 ), 0.14 (0.13 to 0.16 ), 1.13 (1.10 to 1.16 ), 0.19 (0.13 to 0.30 ), and 0.97 (0.95 to 0.98$), 0.24$ (0.24 to 0.25 ), 1.30 (1.21 to 1.38$), 0.16$ (0.11 to 0.22$)$, respectively. On meta-regression analysis, there was no significant difference between PE prevalence and PERC diagnostic performance (coefficient (SE) of $-0.032(0.022), p=0.173$ ) or on relative diagnostic OR $(0.97,95 \%$ CI 0.92 to 1.02$)$.

\section{DISCUSSION}

We conducted a systematic review and meta-analysis of all the literature till date to assess the performance of PERC rule in ruling out the $\mathrm{PE}$ in $\mathrm{ED}$, when the clinical probability is low. We found that PERC rule is highly effective in ruling out the $\mathrm{PE}$ in settings of low clinical suspicion and D-dimer testing is therefore unnecessary when the pretest probability is low. These results are similar to our previous findings with lesser number of studies, which is equivalent to 'level 2 evidence'. ${ }^{12}$

Penaloza et al ${ }^{13}$ reported that PERC rule combined with low gestalt clinical probability seems to identify a group of patients for whom PE could easily be ruled out without additional test, as compared with when PERC rule was applied alone or in combination with revised Geneva score. On analysis, the overall pooled sensitivity and negative likelihood ratio did not change when PERC rule was applied alone and in combination with revised Geneva score and with clinical gestalt to an additional 959 patients by Penaloza et al ${ }^{13}$ in European setting. Pooled specificity, positive and negative likelihood ratio decreased minimally compared with a previous report, ${ }^{12}$ which were clinically insignificant. Possible reasons for unchanged pooled results after including the results of PERC with clinical gestalt could be single study and small number of patients. Therefore, validation of PERC with gestalt clinical probability in another population setting with larger number of patients would be of great value.

Current meta-analysis reports high sensitivity and negative predictive value of PERC with very low missing rate of true PE, which is consistent with our previous report with lesser number of patients. ${ }^{12}$ On subset analysis, sensitivity and negative likelihood ratio did not change between high and low prevalence groups, and thus PERC rule seems to be highly predictive of the absence of PE in low clinical probability population irrespective of the PE prevalence. This further reiterates our findings that 'use of PERC could avoid the frequent expensive diagnostic imaging that typically results when a D-dimer result is positive'. ${ }^{12}$ Addition of one more large study from a different population setting further increases the authenticity of our pooled results, whereas low specificity still remains the major problem. Other limitations of this meta-analysis are small number of included studies and heterogeneity in the specificity and positive likelihood ratio. However, the specificity and positive likelihood ratio have limited importance while measuring the test performance of a predictive test. 
Table 2 Quality assessment study methodology, score obtained by each study on the checklist*

\begin{tabular}{|c|c|c|c|c|c|c|c|c|c|}
\hline & $\begin{array}{l}\text { Hugli, 2011, } \\
\text { Switzerland }\end{array}$ & $\begin{array}{l}\text { Righini, 2005, } \\
\text { Switzerland }\end{array}$ & $\begin{array}{l}\text { Hogg, } \\
\text { 2005, } \\
\text { UK }\end{array}$ & $\begin{array}{l}\text { Wolf, } \\
\text { 2008, } \\
\text { USA }\end{array}$ & $\begin{array}{l}\text { Kline, } \\
\text { 2008, } \\
\text { USA, NZ }\end{array}$ & $\begin{array}{l}\text { Dachs, } \\
2010, \\
\text { USA }\end{array}$ & $\begin{array}{l}\text { Kline, } \\
2004, \\
\text { USAT }\end{array}$ & $\begin{array}{l}\text { Kline, } \\
\text { 2010, } \\
\text { USA }\end{array}$ & $\begin{array}{l}\text { Penaloza, } \\
\text { 2012, France }\end{array}$ \\
\hline $\begin{array}{l}\text { (1) Were the patients selected in an } \\
\text { unbiased fashion (consecutive or random } \\
\text { sampling)? }\end{array}$ & 1 & 1 & 1 & 1 & 1 & 1 & 1 & 1 & 1 \\
\hline $\begin{array}{l}\text { (2) Do they represent a spectrum of } \\
\text { pretest probability the PERC is used for? }\end{array}$ & 0 & 0 & 1 & 1 & 1 & 1 & $0 / 1 \ddagger$ & 1 & 1 \\
\hline $\begin{array}{l}\text { (4) Were the outcomes assessed } \\
\text { without knowledge of the predictor } \\
\text { variables? }\end{array}$ & 1 & 1 & 1 & 1 & 1 & 1 & 1 & 1 & 1 \\
\hline $\begin{array}{l}\text { (5) Were the outcomes defined } \\
\text { accurately (especially PE)? }\end{array}$ & 1 & 1 & 1 & 1 & 1 & 1 & 1 & 1 & 1 \\
\hline
\end{tabular}

\footnotetext{
${ }^{*} \mathrm{Yes}=1, \mathrm{No}=0$.

†The study had two cohorts.

¥Scores represent the score for the low risk and very low risk cohort, respectively.

$\mathrm{PE}$, pulmonary embolism; PERC, pulmonary embolism rule-out criteria.
}
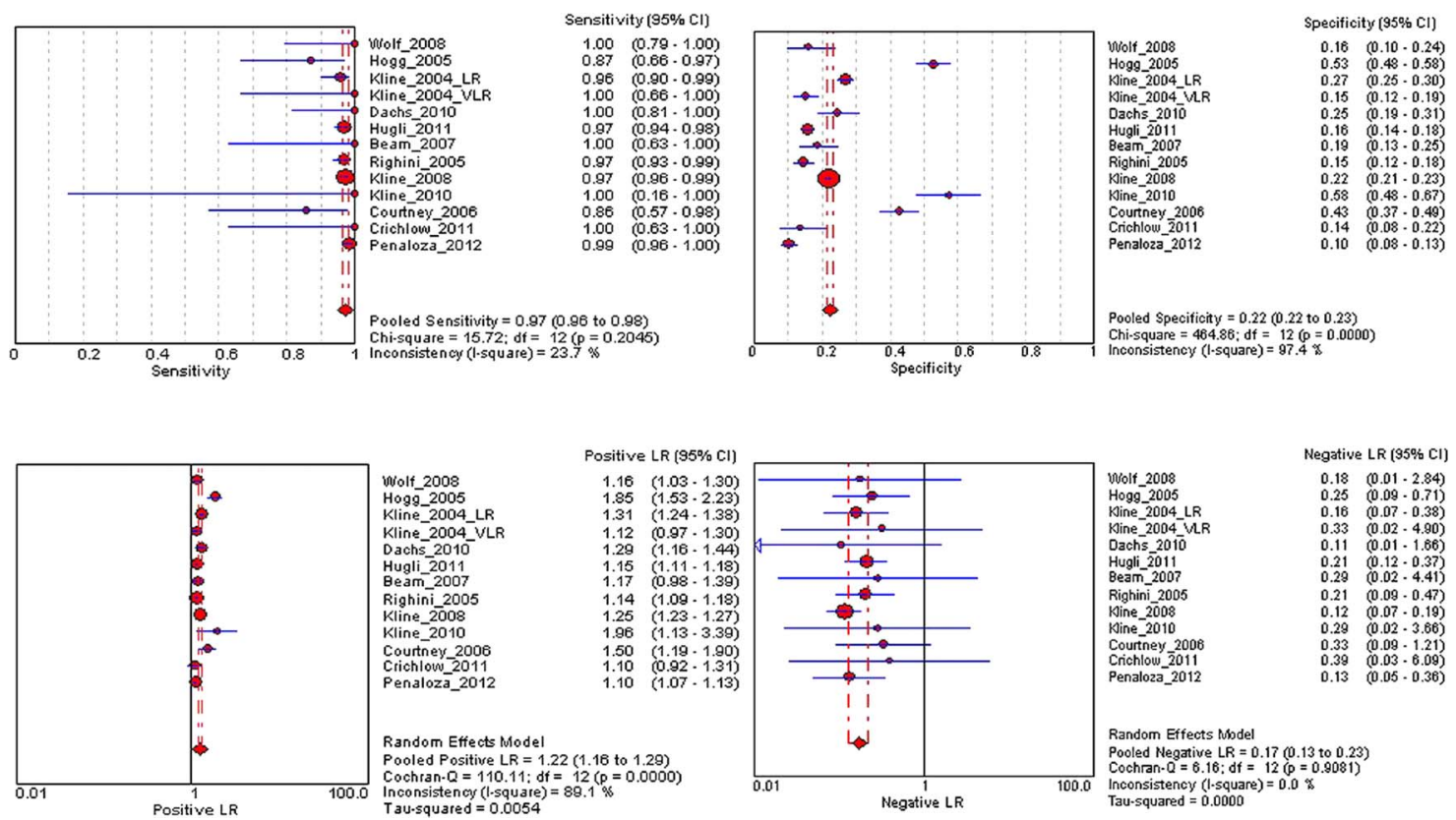

Figure 2 Pooled diagnostic performance of pulmonary embolism rule-out criteria. Access the article online to view this figure in colour.

In conclusion, PERC rule can be used confidently in clinically low probability population settings. Combining PERC rule with gestalt assessment would require further studies in different population settings with a large number of patients.

Acknowledgements Tables 1 \& 2, Adapted from Annals of Emergency Medicine, Vol 59, Singh B, Parsaik AK, Agarwal D et al, Diagnostic Accuracy of Pulmonary Embolism Rule-Out Criteria: A Systematic Review and Meta-analysis, Pages No. 51720.e1-4 , Copyright (2012), with permission from The American College of Emergency Physicians.
Contributors BS: Study concept or design, data collection, analysis or interpretation of data drafting/revising the manuscript. EJP: Literature search, drafting/revising the manuscript. SKM and SSM: Data collection and drafting/revising the manuscript. AP: Study concept or design, data collection, drafting/revising the manuscript.

Competing interests None.

Provenance and peer review Not commissioned; externally peer reviewed.

Disclaimer The views expressed in this manuscript are those of the authors and do not reflect or represent the views of Mayo Clinic. 


\section{REFERENCES}

1. Jones $\mathbf{A E}$, Kline JA. Availability of technology to evaluate for pulmonary embolism in academic emergency departments in the United States. J Thromb Haemost 2003;1:2240-2.

2. Wells PS, Forgie MA, Simms M, et al. The outpatient bleeding risk index: validation of a tool for predicting bleeding rates in patients treated for deep venous thrombosis and pulmonary embolism. Arch Intern Med 2003;163:917-20.

3. Kline JA, Courtney DM, Beam DM, et al. Incidence and predictors of repeated computed tomographic pulmonary angiography in emergency department patients. Ann Emerg Med 2009;54:41-8.

4. Kline JA, Mitchell AM, Kabrhel C, et al. Clinical criteria to prevent unnecessary diagnostic testing in emergency department patients with suspected pulmonary embolism. J Thromb Haemost 2004;2:1247-55.

5. Beam D, Brewer K, Kline JA. EMF-5: Application of the pulmonary embolism rule-out criteria in a rural population. Ann Emerg Med 2007;50:S 132.

6. Dachs RJ, Kulkarni D, Higgins GL III. The pulmonary embolism rule-out criteria rule in a community hospital ED: a retrospective study of its potential utility. $A m \mathrm{~J}$ Emerg Med 2010;29:1023-7.

7. Hogg K, Dawson D, Kline J. Application of pulmonary embolism rule-out criteria to the UK Manchester Investigation of Pulmonary Embolism Diagnosis (MIOPED) study cohort. J Thromb Haemost 2005;3:592-3.

8. Hugli $\mathbf{0}$, Righini M, Le Gal G, et al. The pulmonary embolism rule-out criteria (PERC) rule does not safely exclude pulmonary embolism. J Thromb Haemost 2011; 9:300-4.

9. Kline JA, Courtney DM, Kabrhel $\mathrm{C}$, et al. Prospective multicenter evaluation of the pulmonary embolism rule-out criteria. J Thromb Haemost 2008;6:772-80.
10. Righini M, Le Gal G, Perrier A, et al. More on: clinical criteria to prevent unnecessary diagnostic testing in emergency department patients with suspected pulmonary embolism. J Thromb Haemost 2005;3:188-9; author reply 190-181.

11. Wolf SJ, McCubbin TR, Nordenholz KE, et al. Assessment of the pulmonary embolism rule-out criteria rule for evaluation of suspected pulmonary embolism in the emergency department. Am J Emerg Med 2008;26:181-5.

12. Singh B, Parsaik AK, Agarwal D, et al. Diagnostic accuracy of pulmonary embolism rule-out criteria: a systematic review and meta-analysis. Ann Emerg Med 2012;59:517-20.

13. Penaloza A, Verschuren F, Dambrine S, et al. Performance of the pulmonary embolism rule-out criteria (the PERC rule) combined with low clinical probability in high prevalence population. Thromb Res 2012;129:e189-93.

14. Moher D, Liberati A, Tetzlaff J, et al. Preferred reporting items for systematic reviews and meta-analyses: the PRISMA statement. BMJ 2009;339:b2535

15. Higgins JP, Thompson SG. Quantifying heterogeneity in a meta-analysis. Stat Med 2002;21:1539-58.

16. DM Courtney, JR Pribaz, AC Senh, et al. Prospective evaluation of the Pulmonary Embolism Rule-out Criteria (PERC) rule: an 8-variable block rule to identify subjects at very low risk of pulmonary embolism. Acad Emerg Med 2006;13:S157-8.

17. Kline JA, Peterson CE, Steuerwald MT. Prospective evaluation of real-time use of the pulmonary embolism rule-out criteria in an academic emergency department. Acad Emerg Med 2010;17:1016-19.

18. Crichlow A, Cuker A, Matsuura AC, et al. Underuse of clinical decision rules and D-dimer testing in the evaluation of patients presenting to the emergency department with suspected venous thromboembolism. Acad Emerg Med 201;18:S48. 